\title{
Synthesized Goethite and Natural Iron Oxide as Effective Absorbents for Simultaneous Removal of Co(II) and Ni(II) Ions from Water
}

\author{
Che Randy Nangahi,2, Tagne Guy Merlain², Ndi Julius Nsami², Chongwain Paul Tubwoh ${ }^{3}$, \\ Josepha Foba-Tendo4, Ketcha Joseph Mbadcam ${ }^{1}$
}

${ }^{1}$ Physical and Theoretical Chemistry Laboratory, Department of Inorganic Chemistry, University of Yaounde I,

Yaounde, Cameroon

${ }^{2}$ Local Materials Promotion Authority (MIPROMALO), Ministry of Scientific Research and Innovation, Yaounde, Cameroon

${ }^{3}$ Department of Chemistry, Faculty of Science, University of Bamenda, Bamenda, Cameroon

${ }^{4}$ Department of Chemistry, Faculty of Science, University of Buea, Buea, Cameroon

Email:r5nanga@yahoo.com

How to cite this paper: Nangah, C.R., Merlain, T.G., Nsami, N.J., Tubwoh, C.P., Foba-Tendo, J. and Mbadcam, K.J. (2019) Synthesized Goethite and Natural Iron Oxide as Effective Absorbents for Simultaneous Removal of $\mathrm{Co}(\mathrm{II})$ and $\mathrm{Ni}(\mathrm{II})$ Ions from Water. Journal of Encapsulation and Adsorption Sciences, 9, 127-147. https://doi.org/10.4236/jeas.2019.93007

Received: July 21, 2019

Accepted: September 1, 2019

Published: September 4, 2019

Copyright () 2019 by author(s) and Scientific Research Publishing Inc. This work is licensed under the Creative Commons Attribution International License (CC BY 4.0).

http://creativecommons.org/licenses/by/4.0/

(c) (i) Open Access

\begin{abstract}
This study reports on the adsorption efficiency of a natural iron oxide from Mballam-Cameroon in comparison with synthesized goethite to simultaneously remove cobalt and nickel ions from aqueous solutions. Chemical analysis on the natural iron oxide sample revealed iron as the main element and hematite $(58.52 \%)$ goethite $(19.42 \%)$, kaolinite $(12.69 \%)$ and quartz $(7.79 \%)$ as the component phases in the iron oxide sample. The iron oxide was found to be microporous (BET surface area $43.27 \mathrm{~m}^{2} / \mathrm{g}$ ) with fairly spherical polydisperse particles. Results show maximum absorption for $\mathrm{Co}(\mathrm{II})$ and $\mathrm{Ni}$ (II) ions for both adsorbents occurred at an equilibrium contact time of 80 mins, dose rate of $0.1 \mathrm{~g} / \mathrm{L}$, and $\mathrm{pH}=7$. Goethite was slightly more efficient at removing target metal ions with maximal adsorbed quantities at $117.8 \mathrm{mg} / \mathrm{g}$ of $\mathrm{Co}$ (II) and $100.6 \mathrm{mg} / \mathrm{g}$ of $\mathrm{Ni}(\mathrm{II})$, and $103.9 \mathrm{mg} / \mathrm{g}$ of $\mathrm{Co}(\mathrm{II})$ and $85.2 \mathrm{mg} / \mathrm{g}$ of $\mathrm{Ni}(\mathrm{II})$ ions for natural iron oxide. Equilibrium modelling presented the Freundlich isotherm as the best fit model for both adsorbents and metal ions, indicating heterogeneity of the surface binding sites during adsorption. The pseudo-second order kinetic model was the best-fit model, indicating chemical adsorption between the adsorbent surface and metal ions, hence a good correlation between equilibrium and kinetics. The findings indicate that the efficacy of the natural iron oxide from Mballam is almost equivalent to that of synthetic goethite, validating its applicability for the simultaneous removal of cobalt and nickel ions from aqueous solution.
\end{abstract}




\section{Keywords}

Adsorption, Iron Oxide, Goethite, Powder Diffraction, Heavy Metals, Water Treatment

\section{Introduction}

One of the most significant environmental aspects of mining is its effects on water quality and on the availability of water resources. Mining activities categorically pollute water bodies [1]. They affect fresh and surface water through heavy use of water in processing ore (fresh water withdrawal) and pollution from discharged mine effluent [2], during beneficiation and leaching of toxic materials from tailings and waste rock impoundments [3]. In addition to pollution from targeted metal and other metal by-products, sulfuric acid is produced and leached when sulfide containing rock (from waste dumps, overburden dump and tailings dam) is exposed to air or water and may contaminate ground and surface waters [4] [5] [6]. Given the upsurge of mining companies in Cameroon, it is obvious that mining is fast developing into a major economic activity in the country [7]. In a scenario where a mine is exploited for cobalt and nickel, such as the Nkamouna Cobalt-Nickel-Manganese Project by GEOVIC Cameroon, these metals may be leached into the surrounding waters, resulting to pollution of these water bodies, which has a direct effect on the aquatic life, animals and on man.

Cobalt (Co) and nickel (Ni), when present in quantities greater than the standard norms for drinking water quality pose a threat to human health. Some of the health concerns related to pollution from $\mathrm{Co}$ and $\mathrm{Ni}$ include genotoxicity, carcinogenicity, sensitization and skin irritation. The concentration limit for drinking water is $0.05 \mathrm{mg} / \mathrm{L}$ for Co [8], and $0.07 \mathrm{mg} / \mathrm{L}$ for $\mathrm{Ni}$ [9], and that for mine water effluent $1 \mathrm{mg} / \mathrm{L}$ for Co and $0.2 \mathrm{~g} / \mathrm{L}$ for $\mathrm{Ni}$. The presence of residual metals in streams and rivers around mine sites has been demonstrated by several studies such as the case of a Canada-wide survey carried out in 1994 on the characteristics of acid mine drainage, where a maximum nickel concentration of $36.0 \mathrm{mg} / \mathrm{L}$ was reported for drainage associated with both nickel and gold mines. Cobalt concentrations of $2.20 \mathrm{mg} / \mathrm{L}$ were reported for tailings dam seepage associated with a uranium mine [10]. Surveys carried out by Lupankwa et al., recorded a nickel concentration of $13.85 \mathrm{mg} / \mathrm{L}$ from streams around the Madziwa Nickel Mine to as high as $95.5 \mathrm{mg} / \mathrm{L}$ of nickel and $289 \mathrm{mg} / \mathrm{L}$ of cobalt from streams around the Anthens Gold Mine in the Zambezi basin [11] [12].

Among the conventional treatment technologies used for controlling heavy metals in the environment, adsorption is the most common and applied method in wastewater treatment and it appears to be the most effective economical method [13]-[19]. There is a shift of interest to natural adsorbent materials, prepared at a low cost and equal or more performance when compared to commercial adsorbents [20] [21] [22]. Adsorption of heavy metals onto natural iron 
oxides and goethite had been widely studied for several reasons: iron oxide minerals are abundant in nature, and they are relatively inexpensive [23]; they are present in almost all of the different compartments of the global system, can be readily synthesized in the laboratory and represent efficient sorbents for organic and inorganic species [24]; they have relatively high surface charge, and act as both a contamination adsorbent and nutrient source for oceanic phytoplankton growth. Their ability to remove contamination is a function of the morphology, structural characteristic and method of synthesis [25]. Many toxic cations $\left(\mathrm{Co}^{2+}\right.$, $\left.\mathrm{Zn}^{2+}, \mathrm{Pb}^{2+}, \mathrm{Cd}^{2+}, \mathrm{Sc}^{2+}, \mathrm{U}^{2+}, \mathrm{Sr}^{2+}\right)$, and anions $\left(\mathrm{AsO}_{4}^{-}, \mathrm{CrO}_{4}^{2-}, \mathrm{PO}_{4}^{2-}, \mathrm{CO}_{3}^{2-}\right)$, are removed by using various phases of iron oxides [26]. The adsorption properties of iron oxides are due to a combination of both surface complexation by inner or outer sphere bonding with adsorbate [27], and ion exchange by van der Waals forces.

Although the ability of natural iron oxide for heavy metal pollutant removal is well documented, its ability to simultaneously remove cobalt and nickel ions has not been reported, furthermore, this work accesses the effect on composition and structure on the adsorption properties of these adsorbents. Thus, in this study, the potential of a natural iron oxide sample from Mballam (about $200 \mathrm{~km}$ from the Nkamouna site) to simultaneously remove cobalt and nickel ions from aqueous solutions and compared its effectiveness to synthetic goethite, is examined. This study was carried out as a proactive attempt, aimed at establishing the natural iron oxide from Mballam as an efficient and abundantly available adsorbent capable of use in the treatment of effluents containing cobalt and nickel ions.

\section{Materials and Method}

\subsection{Materials}

All the reagents and chemicals used in this study were of analytical grade. Distilled water was used for synthesis and in the preparation of all solutions. Cobalt(II) nitrate hexahydrate (99\% pure) was purchased from Riedel-de Häen, Nickel(II) nitrate hexahydrate (99\% pure) from LABOSI, Ferric nitrate (99\% pure) from PROLABO, Sodium hydroxide from Fluka, and Sodium hydrogen carbonate of analytical grade.

\subsection{Preparation of Adsorbents}

\subsubsection{Preparation of Natural Iron Oxide}

The rock sample was obtained from the Mballam Iron Ore Deposit in the Eastern Region of Cameroon, at coordinates, N: 02, 14,100 - 383,105, E: 013, 56,926 247,077 and an Elevation of 812. The sample was first crushed using a hammer on a hard surface, then ball-milled for 10 hours using a G91 broiler at $220 \mathrm{~V}$ and $200 \mathrm{~W}$. It was then sieved over a $100-\mu \mathrm{m}$ mesh. The residue was ball-milled for another 10 hours and sieved. These powders were mixed, washed with distilled water and dried under the sun for 24 hours. The resulting dark brown powder was further dried in a CARBOLITE Electric Furnace at $110^{\circ} \mathrm{C}$ for 8 hours. The 
dried powder was ground using a mortar and pestle and further sieved with over a $80 \mu \mathrm{m}$ mesh and dried for 2 hours at $110^{\circ} \mathrm{C}$ in the electric furnace, and stored in a desiccator.

\subsubsection{Goethite Synthesis}

Goethite was synthesized according to a method outlined by Marek et al. [28]: 40 $\mathrm{g}$ of hydrated ferric nitrate, $\mathrm{Fe}\left(\mathrm{NO}_{3}\right)_{3} \cdot 9 \mathrm{H}_{2} \mathrm{O}$ was dissolved in $200 \mathrm{~mL}$ distilled water in a $500 \mathrm{~mL}$ beaker. The solution $(\mathrm{pH}=2.2)$ was agitated by a magnetic agitator for 1 hour to obtain homogeneity, and titrated (while stirring) with $1 \mathrm{M}$ $\mathrm{NaOH}$ to a $\mathrm{pH}$ of 11.9. The amorphous dark brown precipitate formed was aged in an electronic furnace for 16 hours at a temperature of $90^{\circ} \mathrm{C}$. The resulting reddish-brown crystalline precipitate was washed twice with distilled water to remove water-soluble salts. This precipitate was dried for 24 hours at $110^{\circ} \mathrm{C}$; the resulting reddish-brown powder was ground, sieved and stored in a desiccator.

\subsection{Characterization}

Nitrogen sorption experiments were performed using a TriStar 3000 V6.05 A System. The specific surface area of the two powder samples was estimated by applying the Brunauer-Emmet-Teller (BET) equation in the $0.010 \leq \mathrm{P} / \mathrm{Po} \leq$ 0.299 interval of relative pressure and by using $0.1620 \mathrm{~nm}^{2}$ for the cross-sectional area of molecular nitrogen.

Powder diffraction analysis was carried out using a D2 PHASER BRUKER diffractometer, with Co $\mathrm{K} \alpha$ radiation, to determine the various phases present in each sample. The spectra were recorded from $10^{\circ}$ to $90^{\circ}(2 \theta)$, at a scan rate of $0.026^{\circ}$ every 185 seconds for 50 minutes each. Phase identification was carried out by evaluating and presenting the powder data using the DIFFRAC Plus EVA software. The peak locations, lattice parameters, and phase composition were evaluated by comparing scans against the Inorganic Crystal Structure Database (ICSD).

Fourier Transform Infrared Spectroscopy, Attenuated Total Reflection (FTIRATR) was performed using a Perkin Elmer Spectrum One FTIR spectrometer with a microscope system. A ZnSe top plate was used and samples scanned at a resolution of $4 \mathrm{~cm}^{-1}$. Three scan replicates were performed per sample to ensure reproducibility and uniformity.

High resolution SEM (Scanning Electron Microscope) images were recorded to examine the morphology and particle size of the iron oxide using the Carl Zeiss EVOHD15 scanning electron microscope. The ETH was $20 \mathrm{kV}$, probe current $400 \mathrm{pA}$, a working distance of $8.5 \mathrm{~mm}$ and Chamber pressure of $40 \mathrm{~Pa}$. An Oxford Instrument X-Max energy dispersive X-ray equipped with the $80 \mathrm{~mm}^{-2}$ EDX (Energy-dispersive X-ray) detector (SEM-EDX) was also used to perform elemental analysis. Three scan replicates were performed per sample to ensure reproducibility and uniformity.

\subsection{Batch Adsorption Studies}

Batch adsorption studies were carried out simultaneously at room temperature 
to determine the adsorption capacity of the adsorbents. Thus $20 \mathrm{~mL}$ of $700 \mathrm{ppm}$ $\mathrm{Co}\left(\mathrm{NO}_{3}\right)_{3} \cdot 6 \mathrm{H}_{2} \mathrm{O}$ and $20 \mathrm{~mL}$ of $700 \mathrm{ppm} \mathrm{Ni}\left(\mathrm{NO}_{3}\right)_{3} \cdot 6 \mathrm{H}_{2} \mathrm{O}(1: 1$ ratio) were pipetted into a $250 \mathrm{~mL}$ conical flask. These were prepared in sets of eight. A predetermined amount of the adsorbent was weighed and added to these eight bottles. A control experiment was set up by pipetting $20 \mathrm{~mL}$ each of the cobalt and nickel nitrate solution in separate conical flasks. The nine bottles were sealed with a stopper and equilibrated for predetermined periods on a magnetic agitator. After adsorption, the solutions were filtered thrice-using Whatman filter paper, and the resulting supernatant was analyzed twice for cobalt and nickel. A Buck Scientific Atomic Absorption Spectrophotometer, with a VPG system, Model 210 was used to analyze the $\mathrm{Co}$ (II) and $\mathrm{Ni}$ (II) ions in solution. The specifications for each metal are given in Table 1 . The amount of adsorbate adsorbed onto our adsorbents was calculated by the mass balance relationship given in Equation (1).

$$
Q_{e}=\left(\frac{C_{o}-C_{e}}{m}\right) \times V
$$

where:

$Q_{e}$ is the quantity of substance adsorbed $(\mathrm{mg} / \mathrm{g}), C_{o}$ is the initial adsorbate concentration $(\mathrm{mg} / \mathrm{L} \approx \mathrm{ppm}), C_{e}$ the equilibrium concentration of adsorbate $(\mathrm{mg} / \mathrm{L})$, and $V$ is the volume of solution (L), and $\mathrm{m}$ is the mass of sorbent in aqueous solution $(\mathrm{g})$.
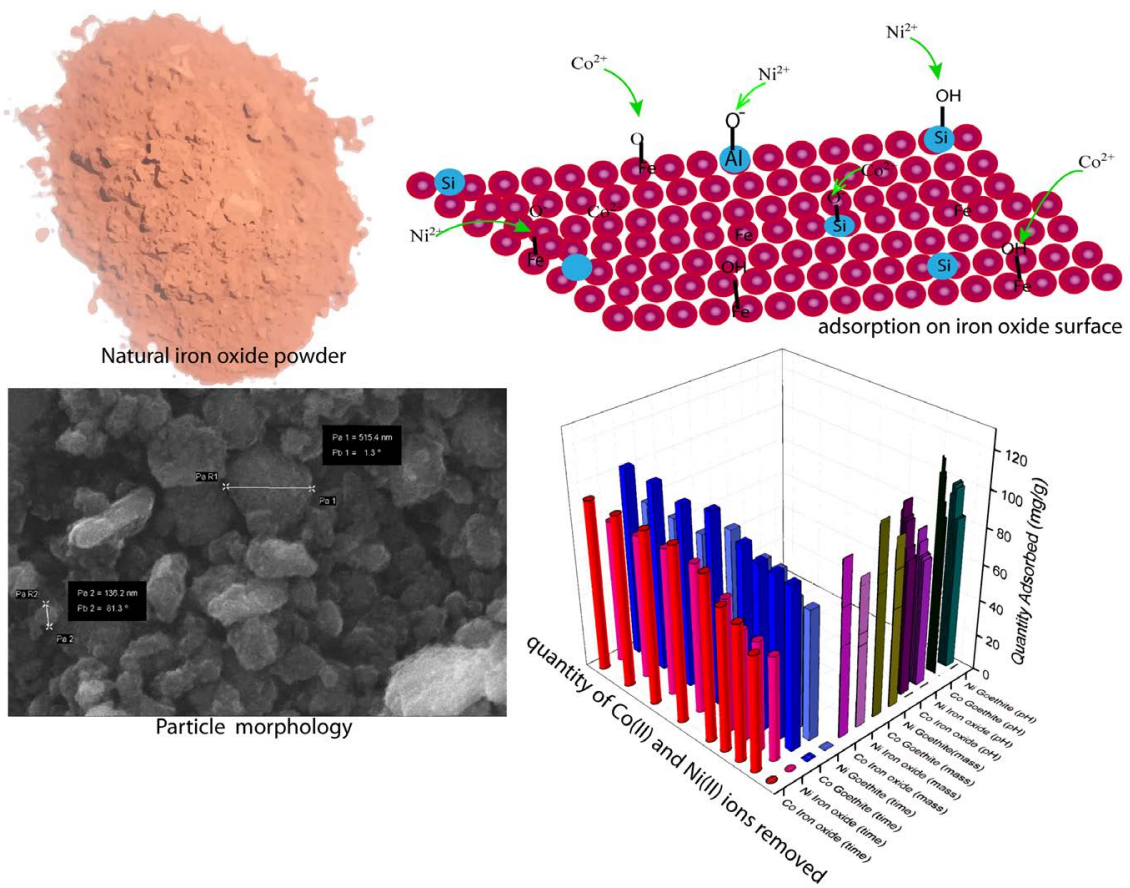

Table 1. Specific wavelengths and AAS analysis conditions for used metal ions.

\begin{tabular}{ccccc}
\hline Element & Wavelength & Average Current & Energy & Hollow-Cathode lamp \\
\hline $\mathrm{Co}(\mathrm{II})$ & $240.7 \mathrm{~nm}$ & $10.1 \mathrm{~mA}$ & 2.463 & Co-BuckSci \\
$\mathrm{Ni}(\mathrm{II})$ & $232.0 \mathrm{~nm}$ & $9.2 \mathrm{~mA}$ & 2.342 & Ni-BuckSci \\
\hline
\end{tabular}




\section{Results and Discussion}

\subsection{Characterization of Adsorbents}

\subsubsection{Surface Area Analysis}

The N2-adsorption/desorption plot for iron oxide and goethite is given in Figure 1, and shows the system follows a type III isotherm. This indicates that adsorbate-adsorbate interactions are stronger than adsorbate-adsorbent interactions, allowing for multilayer formation. Though not wide, a hysteresis loop similar to type $\mathrm{H} 3$ indicative of aggregates of adsorbent containing parallel plates and slit-pores is observed. From BET analysis, goethite was found to be mesoporous (pore volume $48.24 \mathrm{~nm}$ ) with a BET surface area of $59.45 \mathrm{~m}^{2} / \mathrm{g}$ and iron oxide macroporous (pore volume $165.03 \mathrm{~nm}$ ), with a BET surface area of 43.27 $\mathrm{m}^{2} / \mathrm{g}$. The $\mathrm{BJH}$ average adsorption pore diameter $(4 \mathrm{~V} / \mathrm{A})$ is $13.35 \mathrm{~nm}$ and 17.11 $\mathrm{nm}$ for iron oxide and goethite respectively.

\subsubsection{X-Ray Powder Diffraction (XRPD)}

The powder patterns of the natural iron oxide and synthetic goethite on a $2 \theta$ scale are represented in Figure 2 and Figure 3 respectively. The sharp diffraction peaks observed for both powders imply well crystalline samples. Phase identification using DIFFRAC Plus EVA software and quantitative analysis (peak locations, lattice parameters, and phase composition) from comparing scans against the Inorganic Crystal Structure Database (ICSD) for iron oxide powder data reveals the presence of goethite, hematite, kaolinite and quartz in the iron oxide sample.

Hematite is the major component at $58.52 \%$, followed by goethite (19.42\%), then by kaolinite (12.69\%), and lastly quartz (7.79\%). Phase identification of the

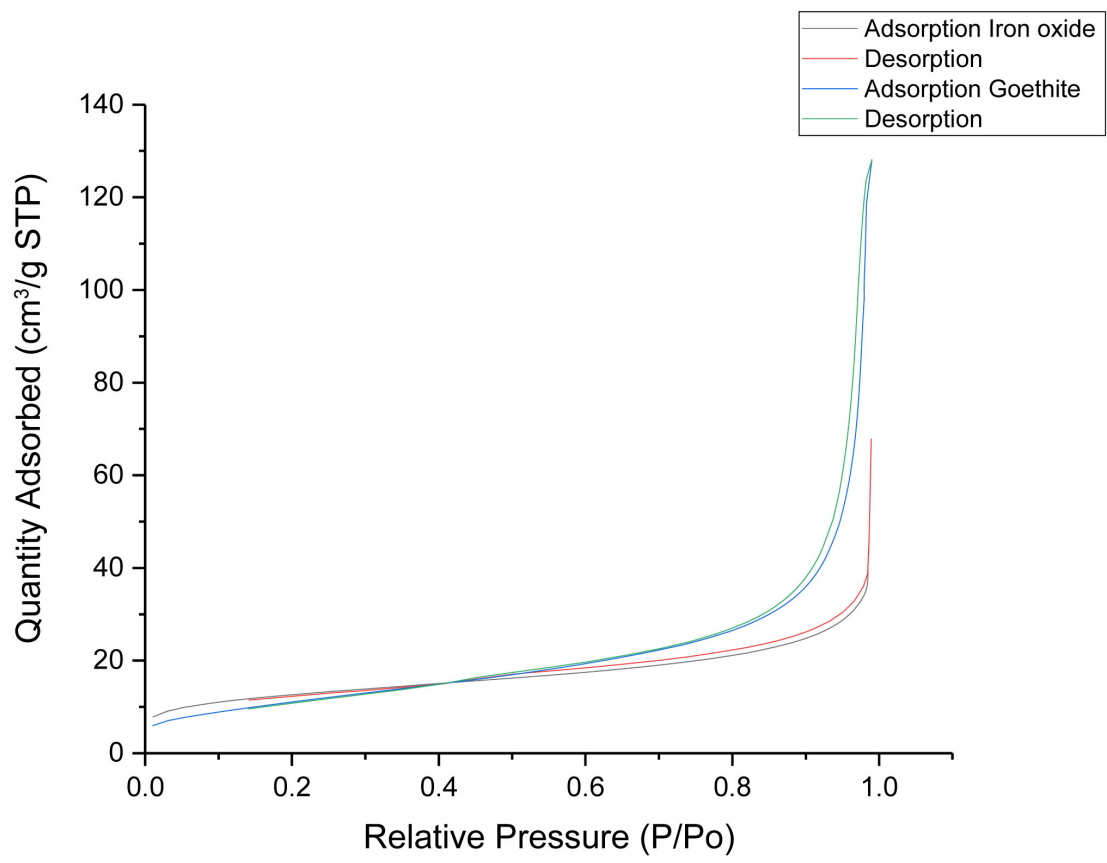

Figure 1. N2-adsorption/desorption plot for iron oxide and goethite. 


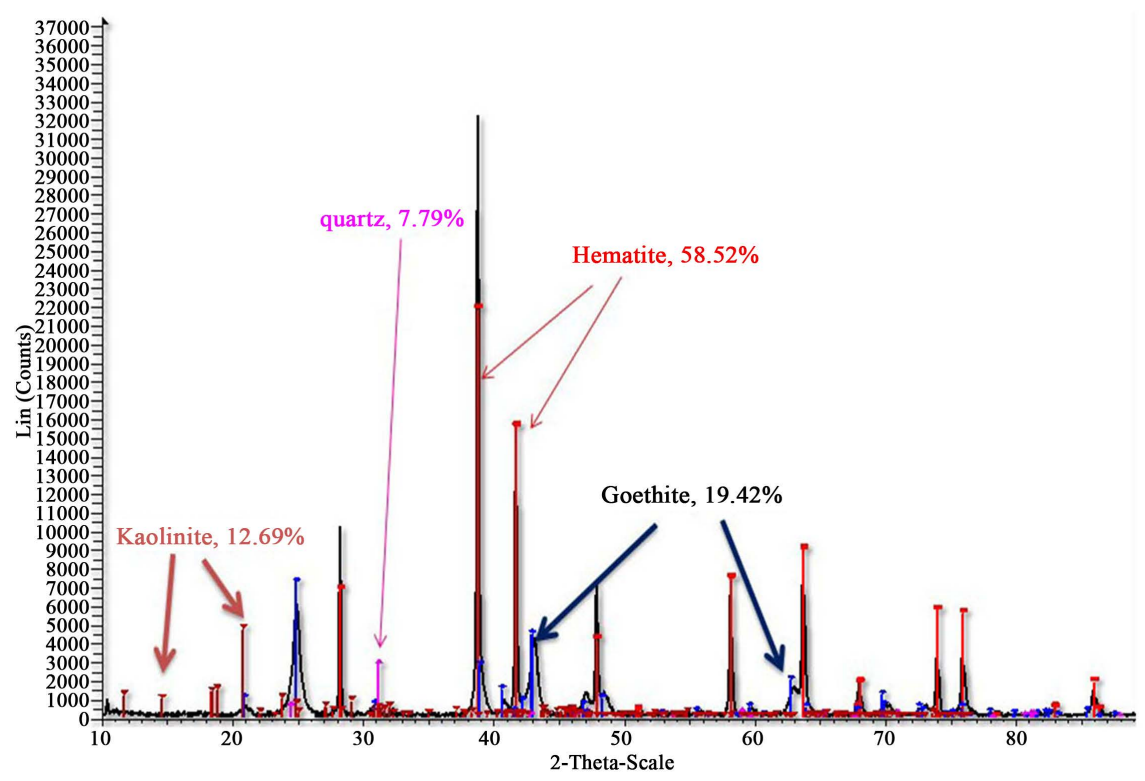

Figure 2. XRD spectra of natural iron oxide showing four oxide phases.

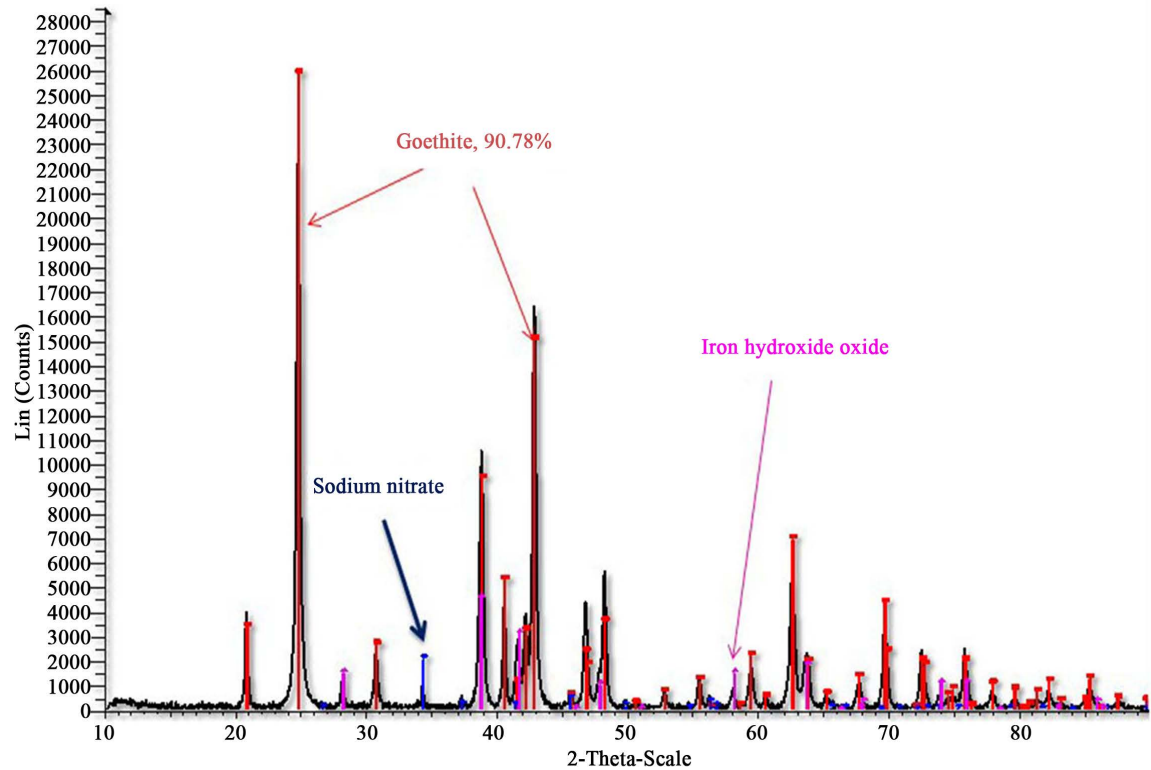

Figure 3. XRD spectra of synthetic goethite showing three oxide phases.

goethite sample revealed the three phases, the goethite (90.73\%), an intermediate iron hydroxide oxide and sodium nitrate. The intermediate phase may be as result of incomplete conversion of the amorphous iron hydroxide phase during aging. Sodium nitrate implies washing was not complete. The composition and lattice parameters of all the components in each sample are listed Table 2.

\subsubsection{FTIR}

The overlaid ATR-FTIR spectra of goethite and iron oxide is illustrated Figure 4. The peak assignments were done after correlating the spectra with handbook values and previous reports. The absorption band around $3116 \mathrm{~cm}^{-1}, 3123 \mathrm{~cm}^{-1}$ 
Table 2. Phase composition and lattice parameters.

\begin{tabular}{|c|c|c|c|c|c|c|c|}
\hline & \multirow{2}{*}{ Sample } & \multirow{2}{*}{ Lattice } & \multicolumn{3}{|c|}{ Lattice parameters } & \multirow{2}{*}{ Space group } & \multirow{2}{*}{ ICSD code } \\
\hline & & & a & b & c & & \\
\hline \multirow{4}{*}{ Iron oxide } & Hematite $\alpha-\mathrm{Fe}_{2} \mathrm{O}_{3}$ & Rhombohedral & 5.03530 & 5.0350 & 13.74950 & $\mathrm{R}-3 \mathrm{c}$ & 082902 \\
\hline & Goethite $\mathrm{FeOOH}$ & Orthorhombic & 4.61580 & 9.95450 & 3.02300 & Pbnm & 071810 \\
\hline & Kaolinite $\mathrm{Al}_{2}\left(\mathrm{Si}_{2} \mathrm{O}_{5}\right)(\mathrm{OD})_{4}$ & Triclinic & 5.16910 & 8.95950 & & & \\
\hline & Quartz $\mathrm{SiO}_{2}$ & Hexagonal & 4.91370 & 5.40470 & 4.91370 & P3221 & 089276 \\
\hline \multirow{3}{*}{ Goethite } & Goethite & Orthorhombic & 4.60480 & 9.95950 & 3.02300 & Pbnm & 033692 \\
\hline & Iron hydroxide oxide $\mathrm{Fe}_{1.883}(\mathrm{OH})_{0.5} \mathrm{O}_{2.5}$ & Rhombohedral & 5.03400 & & 13.75000 & $\mathrm{R}-3 \mathrm{c}$ & 033693 \\
\hline & Sodium nitrate $\mathrm{Na}\left(\mathrm{NO}_{3}\right)$ & Rhombohedral & 5.07010 & 5.07010 & 16.32902 & $\mathrm{R}-3 \mathrm{c}$ & 078801 \\
\hline
\end{tabular}

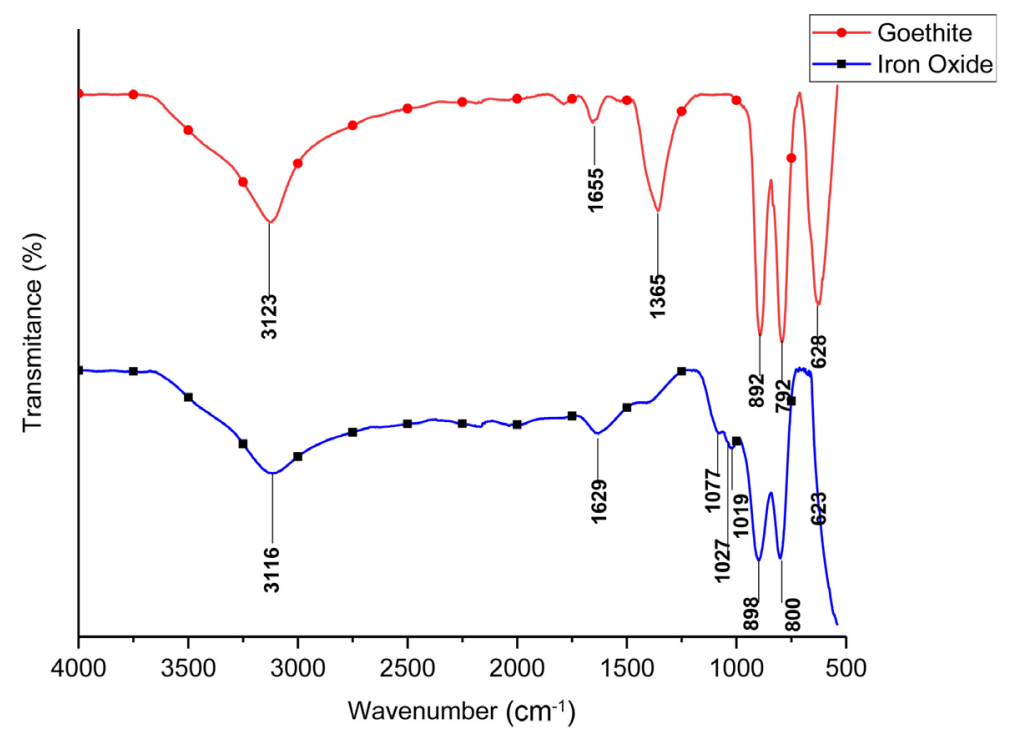

Figure 4. ATR-FTIR Spectra of natural iron oxide and goethite presenting major functional groups.

is assigned to the $\mathrm{O}-\mathrm{H}$ stretching modes of water owing to bulk hydroxyl stretch and $1629 \mathrm{~cm}^{-1}, 1655 \mathrm{~cm}^{-1}$ to the bending modes of water owing to stretching vibration of hydroxyl group on goethite. The bands at $898,891 \mathrm{~cm}^{-1}(8 \mathrm{OH}$ in-plane bend) and $800,794 \mathrm{~cm}^{-1}$ ( $/ \mathrm{OH}$ out-of-plane bend) which vibrate in and out respectively, can be assigned to the $\mathrm{Fe}-\mathrm{OH}$ bending vibration of goethite [29] [30]. The bands at $623 \mathrm{~cm}^{-1}$ and $628 \mathrm{~cm}^{-1}$ are due to stretching vibrations of the Fe-O bond characteristic of the metal oxide. The three bands at $1077 \mathrm{~cm}^{-1}$ (perpendicular Si-O stretch), $1027 \mathrm{~cm}^{-1}$ (in-plane Si-O stretch), and $1019 \mathrm{~cm}^{-1}$ (in-plane $\mathrm{Si}-\mathrm{O}$ stretch) in the spectra of the natural iron oxide depicts the Si-O deformation bands of kaolinite, which is also characteristic of the $\mathrm{Si}-\mathrm{O}$ asymmetrical stretching vibration of quartz [31]. The absence of a peak at $2900 \mathrm{~cm}^{-1}$ characteristic of the $\mathrm{C}-\mathrm{H}$ stretching band, implies no organic compound is present in the sample [32]. The sharp band at $1365.52 \mathrm{~cm}^{-1}$ in the spectrum of goethite is characteristic of nitrate ion (impurity). Hence, in addition to the surface hydroxy 
groups (from adsorption of water and structural $\mathrm{OH}$ ), and $\mathrm{Fe}-\mathrm{O} / \mathrm{Fe}-\mathrm{OH}$ metal-oxide functional groups on the goethite and natural iron oxide, the natural iron oxide also has $\mathrm{SiOH}$ potential adsorption sites (from the kaolinite).

\subsubsection{SEM-EDX}

The morphology of the iron oxide and goethite as studied using SEM is presented in Figure 5. The iron oxide particles (Figure 5(a)) are fairly spherical (granular in shape) and polydisperse, with particle diameter of $136.2 \mathrm{~nm}$ for the smallest visible particle to $515 \mathrm{~nm}$ for the largest particle. Chen and Li, 2010 [33] also observed granular-shaped nano particles of hematite synthesized via coprecipitation. The morphology of goethite particles in the natural iron oxide sample is rod-like. Energy dispersive X-ray elemental analysis (an average of five measured points) depicts iron (46.69 wt\%) as the main component of iron oxide sample followed by oxygen (35.76 wt\%), Si (14.47 wt\%) and $\mathrm{Al}$ (1.87 wt\%). At low magnification (Figure 5(b)), goethite particles look very similar to those of the iron oxide with fairly spherical polydisperse particles. However, at higher magnification $(\mathrm{Mag}=200 \mathrm{KX})$, needle-like (acicular) particles typical of goethites are visible. The particle diameter varies from 37.52 to $150.5 \mathrm{~nm}$.

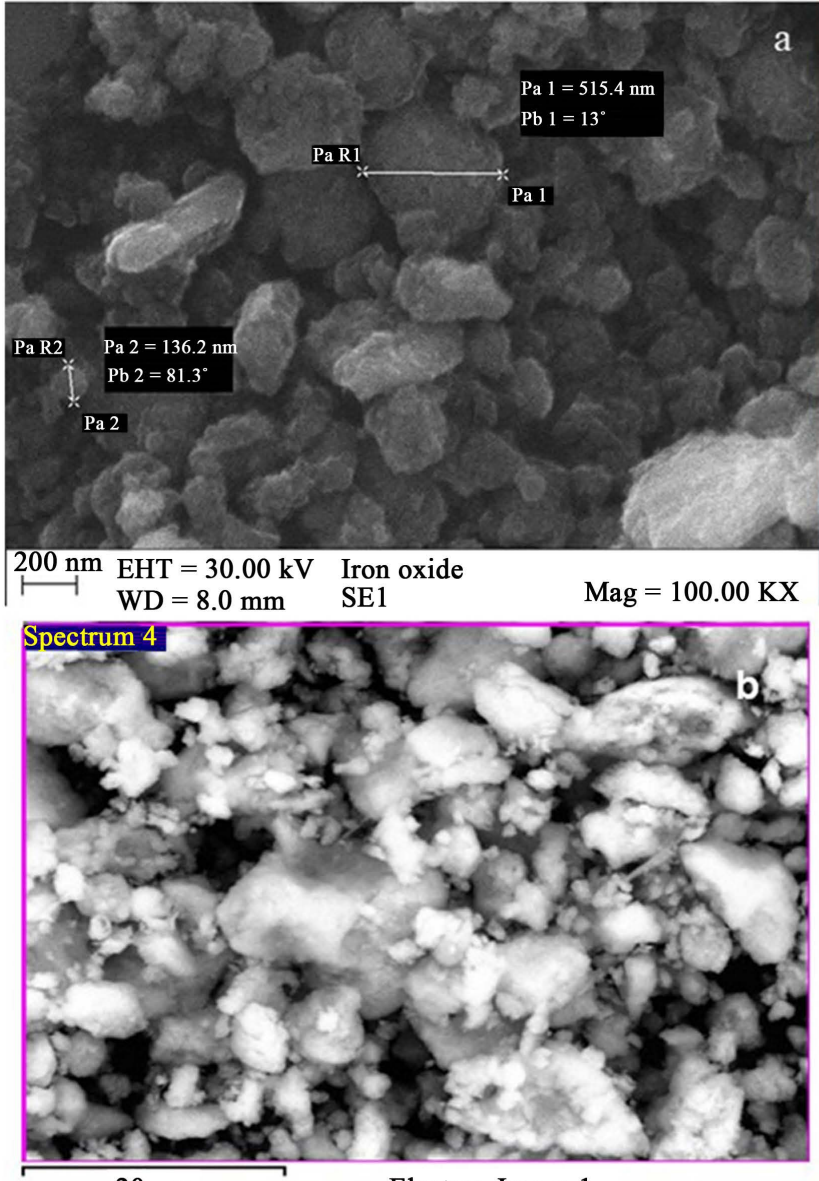

$20 \mu \mathrm{m}$
Electron Image 1
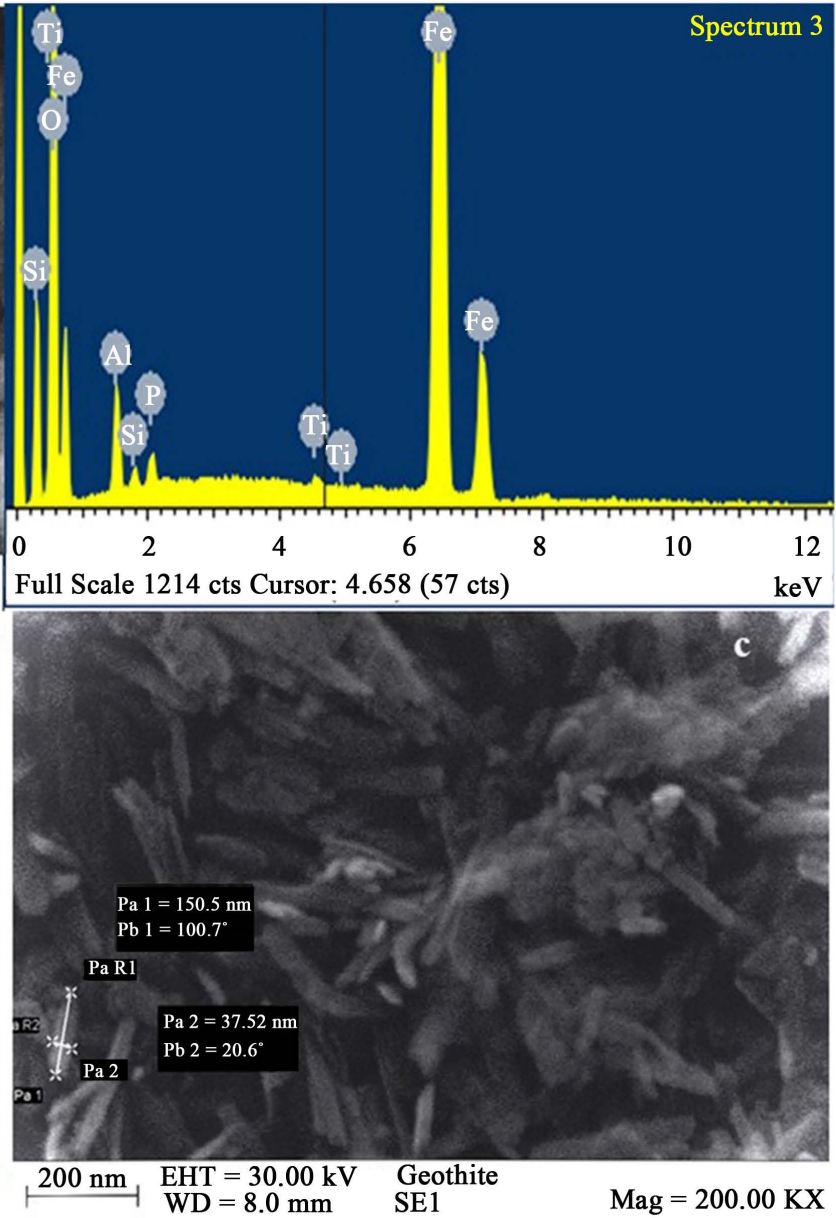

Figure 5. SEM Micrograph and EDX spectra showing fairly spherical particles of iron oxide and needle-like goethite particles. 


\subsection{Batch Adsorption Studies: Effect of Contact Time, Adsorbent Mass and $\mathrm{pH}$}

The effect of contact time, adsorbent mass and $\mathrm{pH}$ on the simultaneous adsorption of $\mathrm{Co}(\mathrm{II})$ and $\mathrm{Ni}(\mathrm{II})$ ions on natural iron oxide and goethite are illustrated in Figure 6. To study the effect of contact time, batch experiments were conducted at different contact times from 10 to 120 minutes at constant concentration of $700 \mathrm{ppm}$, and $0.1 \mathrm{~g}$ of adsorbent at room temperature. From the graph, the extent of removal of the $\mathrm{Co}(\mathrm{II})$ and $\mathrm{Ni}$ (II) ion increases initially, then stabilizes after 80 minutes for both adsorbents. At the onset and at lower contact times, the surface adsorption sites are unoccupied and available for metal ion adsorption. As the contact time increases, the surface adsorption sites become occupied; the uptake rate is controlled by the rate at which the adsorbate is transported from the exterior to the interior sites of the adsorbent particles (diffusion) which in this case is low, resulting to the plateau-shape of the curve at higher contact times. Equilibrium was attained at a contact time of 80 minutes for both adsorbents. The effect of contact time was also studied at $50 \mathrm{ppm}$ and $0.1 \mathrm{~g}$ of natural iron oxide and the equilibrium was attained at $80 \mathrm{mins}$ with a percentage removal of $90.33 \%$ of $\mathrm{Co}(\mathrm{II})$ and $75.60 \%$ of $\mathrm{NI}(\mathrm{I})$ ions.
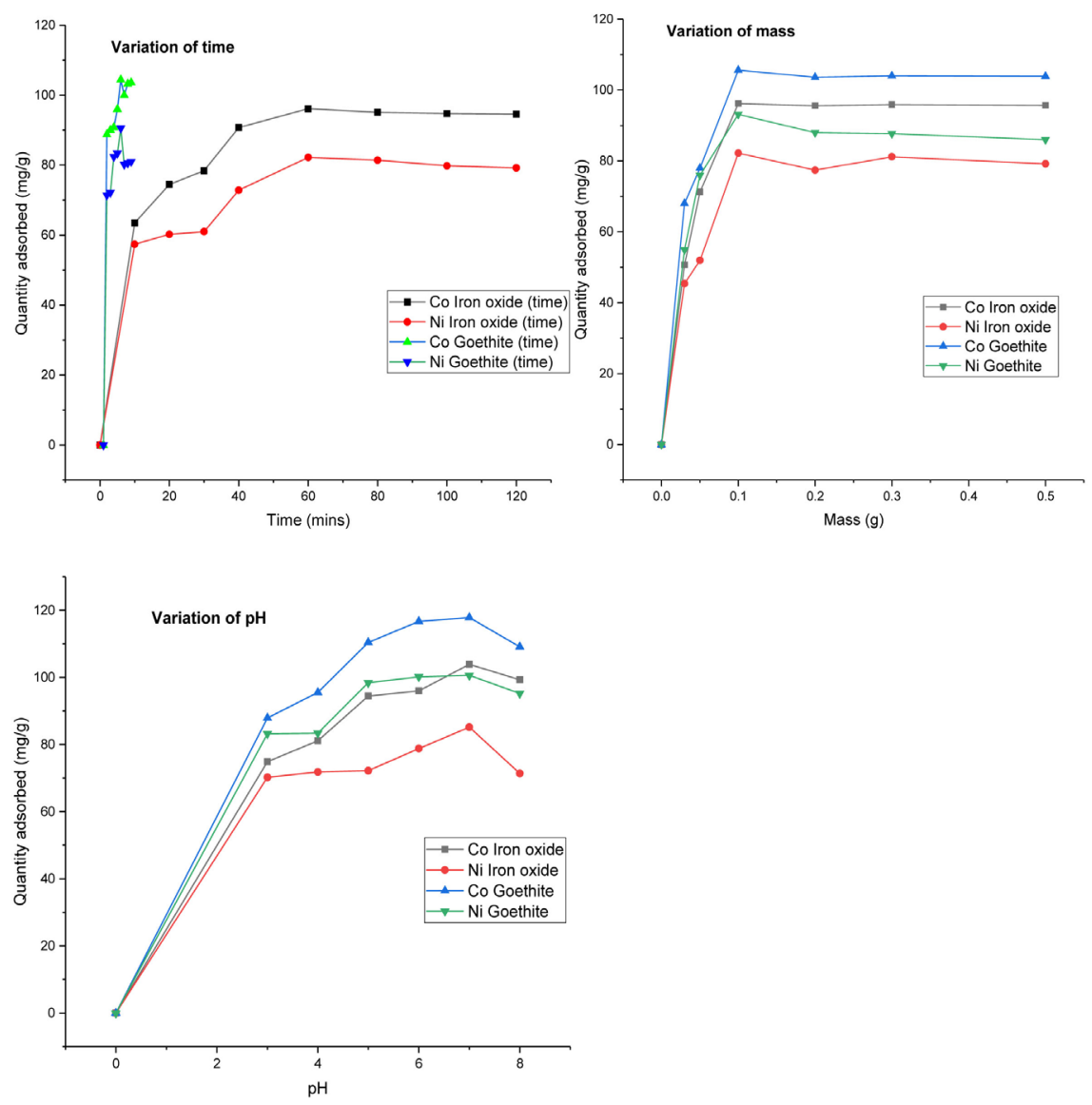

Figure 6. Effect of contact time, adsorbent mass and $\mathrm{pH}$ on the simultaneous adsorption of $\mathrm{Co}(\mathrm{II})$ and $\mathrm{Ni}(\mathrm{II})$ ions on natural iron oxide and goethite. 
For effect of adsorbent mass, the removal of the $\mathrm{Co}(\mathrm{II})$ and $\mathrm{Ni}$ (II) ions was studied at a concentration of $700 \mathrm{ppm}$, contact time of 80 minutes while varying the dose of adsorbent in the range 0.03 to $0.5 \mathrm{~g}$. Equilibrium was attained for $\mathrm{Co}$ (II) and $\mathrm{Ni}$ (II) ions at $0.1 \mathrm{~g}$ of both adsorbents, hence, increasing the mass up to $0.1 \mathrm{~g}$ makes available more adsorption active sites on the adsorbents [34] and beyond $0.1 \mathrm{~g}$ aggregation of adsorbent particles prevents further adsorption.

The $\mathrm{pH}$ is another important parameter controlling the uptake of $\mathrm{Co}(\mathrm{II})$ and $\mathrm{Ni}$ (II) ion from aqueous solution. The point of zero charge was determined using the method developed by Ouardi et al. [35] at a $\mathrm{pH}$ range of $3-11$. The pHzpc of goethite and iron oxide was found out to be 6.7 and 6.1 respectively. The adsorption potential of both adsorbents was studied at various $\mathrm{pH}$ values ( 3 to 8) keeping the system at the following conditions: initial concentration of 700 $\mathrm{ppm}$, adsorbate dose of $0.1 \mathrm{~g}$ contact time 80 minute. At low $\mathrm{pH}(\mathrm{pH}<\mathrm{pHzpc})$, a positive charge is developed on the surface of the adsorbents, resulting to poor sorption of the metal ions due to repulsion. As $\mathrm{pH}$ increases, the surface of the adsorbents become increasingly negatively charged $\left(\mathrm{OH}^{-}\right.$ions dominating), enhancing electrostatic attraction between the metal ion and the adsorbent surface resulting in increased removal of the metal ions. Abdus-Salam and Adekola [36] reported that as the $\mathrm{pH}$ increases, divalent metal retention on the surface of natural goethite through the processes of adsorption and inner sphere surface complexation increases. An optimum $\mathrm{pH}$ of 7 is recorded for both adsorbents, after which adsorption decreases, probably due to the precipitation of $\mathrm{Ni}$ (II) ions to $\mathrm{Ni}(\mathrm{OH})_{2}$. This indicates the applicability of adsorbents developed for water systems at neutral $\mathrm{pH}$.

Adsorption of metal ions onto goethite is a surface complexation reaction between the aqueous metal ions and hydroxyl-specific surface sites. The amphoteric reaction at the goethite surface is depicted in the equations below.

$$
\begin{aligned}
\mathrm{FeOH}_{2}^{+}(\mathrm{s}) & \rightarrow \mathrm{FeOH}(\mathrm{s})+\mathrm{H}^{+}(\mathrm{aq}) \\
\mathrm{FeOH}(\mathrm{s}) & \rightarrow \mathrm{FeO}^{-}(\mathrm{s})+\mathrm{H}^{+}(\mathrm{aq})
\end{aligned}
$$

where $\mathrm{FeOH}$ represents a single protonated surface oxide site and $\mathrm{FeO}^{-}$and $\mathrm{FeOH}^{+}$represents ionized surface functional groups. The possible adsorption reactions include

$$
\begin{gathered}
\mathrm{FeO}^{-}+\mathrm{Co}^{2+} \rightarrow \mathrm{FeCo}^{+} \\
\mathrm{FeO}^{-}+\mathrm{Co}(\mathrm{OH})^{+} \rightarrow \mathrm{FeOCo}(\mathrm{OH}) \\
\mathrm{FeOH}+\mathrm{Co}^{2+} \rightarrow \mathrm{FeOCo}^{+}+\mathrm{H}^{+} \\
\mathrm{FeOH}+\mathrm{Co}(\mathrm{OH})^{+} \rightarrow \mathrm{FeCo}(\mathrm{OH})+\mathrm{H}^{+}
\end{gathered}
$$

Metal adsorption is thus favored if the adsorbent is negatively charged at higher $\mathrm{pH}$. These reactions are analogous to those involving $\mathrm{Ni}(\mathrm{II})$ ions.

The results obtained from batch adsorption studies gave an indication of the effectiveness of each adsorbent with respect to $\mathrm{Co}(\mathrm{II})$ and $\mathrm{Ni}(\mathrm{II})$ ions. These are summarized in Table 3. For both adsorbents, the quantity of $\mathrm{Co}$ (II) ions adsorbed 
Table 3. Quantity adsorbed at equilibrium for various parameters.

\begin{tabular}{cccc}
\hline \multirow{2}{*}{ Parameter } & Metal ion & \multicolumn{2}{c}{ Optimum Quantity Adsorbed at Equilibrium $(\mathrm{mg} / \mathbf{g})$} \\
\cline { 3 - 4 } & & Iron oxide & Goethite \\
\hline \multirow{2}{*}{ Contact Time } & $\mathrm{Co}(\mathrm{II})$ & 95.1 & 100 \\
& $\mathrm{Ni}(\mathrm{II})$ & 81.4 & 80.2 \\
\multirow{3}{*}{ Adsorbent Dose } & $\mathrm{Co}(\mathrm{II})$ & 96.2 & 105.6 \\
& $\mathrm{Ni}(\mathrm{II})$ & 82.2 & 93.2 \\
$\mathrm{pH}$ & $\mathrm{Co}(\mathrm{II})$ & 103.9 & 117.8 \\
& $\mathrm{Ni}(\mathrm{II})$ & 85.2 & 100.6 \\
\hline
\end{tabular}

from solution was higher than that of $\mathrm{Ni}$ (II) ions under the same conditions. Cobalt has a slightly lower electronegativity value (1.88) than nickel (1.91) and higher ionic radius, hence, it is more reactive (easily give off its electrons to react with negatively charged functionalities on the surface of the adsorbent). Also, it is higher than nickel in the reactivity series and will therefore displace some of the adsorbed $\mathrm{Ni}(\mathrm{II})$ ions. Goethite showed the highest adsorption capacity for both $\mathrm{Co}(\mathrm{II})$ and $\mathrm{Ni}(\mathrm{II})$ ions. This is so for several reasons. As demonstrated by $\mathrm{BET}$, it has a larger specific surface area, possess more number of micropores and mesopores and higher total surface energy which make it more prone to adsorb the $\mathrm{Co}(\mathrm{II})$ and $\mathrm{Ni}(\mathrm{II})$ ions on to its surface. The presence of other phases (such as quartz and kaolinite) in the natural iron oxide sample may also have caused a decrease in its adsorptive capacity.

Dwivedi et al. [37] compared the adsorption capacity of pristine carbon (FWC) and amine modified carbon (AFWC) from fireweed to that of commercial grade activated carbon (PAC) for binary adsorption of cobalt(II) and nickel (II) ions. The optimum conditions for batch adsorption were $0.8 \mathrm{~g} / \mathrm{L}$ adsorbent, $5 \mathrm{mg} / \mathrm{L}$ adsorbate, $\mathrm{pH} 5.78$ and $18 \mathrm{~h}$. The adsorption capacities varied from 2.21 to $10.12 \mathrm{mg} / \mathrm{g}$ and percentage removal varied from $17.7 \%$ to $96.8 \%$ (Table 4 ). They reported the AFWC, with a BET surface area of $117.7 \mathrm{mg} / \mathrm{g}$, to have a five-fold and three-fold capacity over FWC and PAC respectively for Co(II) and $\mathrm{Ni}$ (II) ion removal. Table 4 compares the adsorption capacity of natural iron oxide used in this study and others reported in the literature for alt and/or nickel ion adsorption. From these results, the natural iron oxide is seen to have a considerable high adsorption capacity.

\subsection{Adsorption Isotherms}

The equilibrium data was model using the linear forms of the Langmuir and Freundlich isotherm models as given in Equation (2) and Equation (3) below. The model parameters are given in Table 5 .

$$
\begin{aligned}
& \frac{1}{Q_{e}}=\frac{1}{Q_{m} K C_{e}}+\frac{1}{Q_{m}} \\
& \ln Q_{e}=\ln K_{f}+\frac{1}{n} \ln C_{e}
\end{aligned}
$$


Table 4. Comparing the adsorption capacity of natural iron oxide used in this study and others reported in the literature for cobalt and/or nickel ion adsorption.

\begin{tabular}{|c|c|c|c|c|}
\hline Adsorbate & Adsorbent & $\begin{array}{c}\text { Removal } \\
\text { capacity (mg/g) }\end{array}$ & $\begin{array}{l}\text { Percentage } \\
\text { removal (\%) }\end{array}$ & Ref \\
\hline $\mathrm{Co}(\mathrm{II})$ & \multirow{2}{*}{ Natural iron oxide } & 103.9 & 90.33 & \multirow{2}{*}{ This work } \\
\hline $\mathrm{Ni}(\mathrm{II})$ & & 85.2 & 75.60 & \\
\hline $\mathrm{Co}(\mathrm{II})$ & \multirow{2}{*}{ Synthetic goethite } & 117.8 & N/A & \multirow{2}{*}{ This work } \\
\hline $\mathrm{Ni}(\mathrm{II})$ & & 100.6 & N/A & \\
\hline $\mathrm{Co}(\mathrm{II})$ & \multirow{2}{*}{ AFWC } & 9.89 & 96.5 & \multirow{6}{*}{ [37] } \\
\hline $\mathrm{Ni}(\mathrm{II})$ & & 10.12 & 96.8 & \\
\hline $\mathrm{Co}(\mathrm{II})$ & \multirow{2}{*}{ FWC } & 2.91 & \multirow{2}{*}{$\begin{array}{l}26.3 \\
26.8\end{array}$} & \\
\hline $\mathrm{Ni}(\mathrm{II})$ & & 2.97 & & \\
\hline $\mathrm{Co}(\mathrm{II})$ & \multirow{2}{*}{ PAC } & 1.86 & 16.7 & \\
\hline $\mathrm{Ni}(\mathrm{II})$ & & 2.29 & 17.7 & \\
\hline $\mathrm{Co}(\mathrm{II})$ & $\begin{array}{c}\text { Mesoporous silica } \\
\text { nano-conjugate material }\end{array}$ & 170.17 (calculated) & 96 & {$[38]$} \\
\hline $\mathrm{Ni}(\mathrm{II})$ & $\begin{array}{l}\mathrm{Ni}^{2+} \text {-imprinted } \\
\text { chitosan Foam }\end{array}$ & 69.93 (calculated) & N/A & [39] \\
\hline $\mathrm{Ni}(\mathrm{II})$ & MWCNTs & 2.90 & N/A & [40] \\
\hline $\mathrm{Ni}(\mathrm{II})$ & $\mathrm{HNO}_{3}$-treated MWCNTs & 12.50 & N/A & [41] \\
\hline $\mathrm{Co}(\mathrm{II})$ & MWCNTs/iron oxide & 2.88 & N/A & {$[42]$} \\
\hline $\mathrm{Co}(\mathrm{II})$ & Oxidized CNTs sheets & 69.63 & N/A & [43] \\
\hline $\begin{array}{l}\mathrm{Co}(\mathrm{II}) \\
\mathrm{Ni}(\mathrm{II})\end{array}$ & Chitosan-coated perlite beads & $\begin{array}{c}56.18 \\
66.66 \text { (calculated) }\end{array}$ & N/A & {$[44]$} \\
\hline $\mathrm{Co}(\mathrm{II})$ & $\gamma$ - $\mathrm{Fe}_{2} \mathrm{O}_{3}$ nanotubes & 56.83 & N/A & {$[45]$} \\
\hline $\mathrm{Ni}(\mathrm{II})$ & & 65.62 & & \\
\hline
\end{tabular}

Table 5. Langmuir and freundlich model parameters.

\begin{tabular}{lccccccc}
\hline \multirow{2}{*}{ Parameter } & \multicolumn{3}{c}{ Langmuir Isotherm } & \multicolumn{3}{c}{ Freundlich Isotherm } \\
\cline { 3 - 8 } & & $k_{L}(\mathrm{~L} / \mathrm{mg})$ & $Q_{m}(\mathrm{mg} / \mathrm{g})$ & $\boldsymbol{r}^{2}$ & $K_{f}(\mathrm{~L} / \mathrm{g}) \times 10^{7}$ & $1 / \mathrm{n}$ & $\boldsymbol{r}^{2}$ \\
\hline \multirow{3}{*}{ Iron Oxide } & $\mathrm{Co}(\mathrm{II})$ & -0.44 & 27.40 & 0.9891 & 3.9 & -2.108 & 0.9963 \\
& $\mathrm{Ni}(\mathrm{II})$ & -0.82 & 21.10 & 0.9931 & 212 & -2.794 & 0.9858 \\
& $\mathrm{Co}(\mathrm{II})$ & -0.20 & 37.59 & 0.987 & 0.4 & -1.755 & 0.9957 \\
\multirow{2}{*}{ Goethite } & $\mathrm{Ni}(\mathrm{II})$ & -0.36 & 29.85 & 0.9961 & 4.4 & -2.124 & 0.9965 \\
\hline
\end{tabular}

where: $Q_{m}$ is the maximum adsorption capacity corresponding to complete monolayer coverage, $K$ is the Langmuir constant related to energy of the adsorption ( $L$ of adsorbate per mg of adsorbent) $n$ is the heterogeneity factor representing the deviation from linearity of adsorption, $K_{f}$ indicates the adsorption capacity of adsorbent related to the bonding energy

The $R^{2}$ values for the Freundlich model are the highest (in the range 0.976 to 0.9965), thus the Freundlich isotherm model more accurately describes the adsorption for both adsorbents and for both adsorbates (Figure 7). The Freundlich 

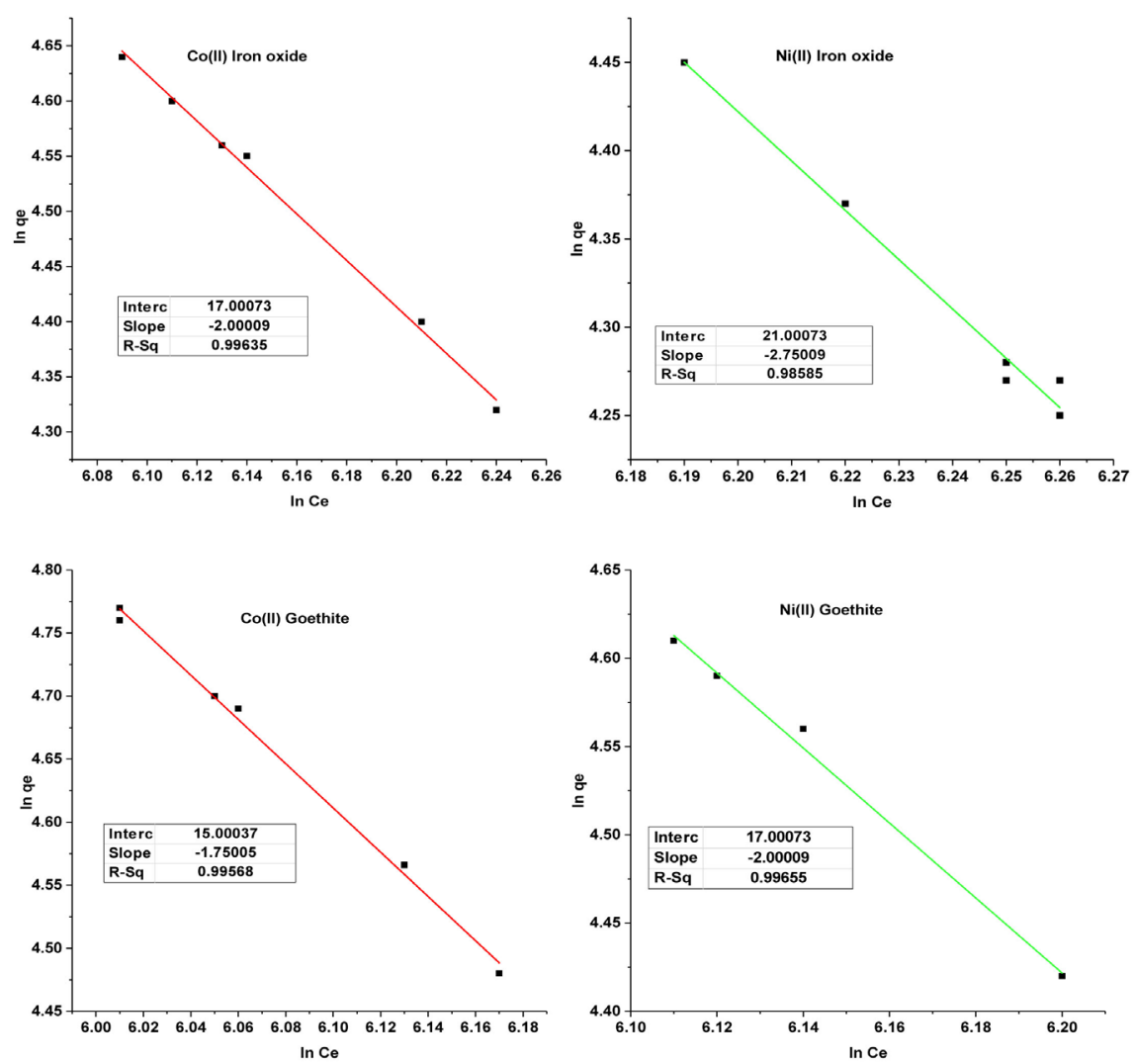

Figure 7. Linear model plots of the Freundlich Isotherm.

isotherm relates the amount of material adsorbed to the concentration of the material in solution. Krishine et al. [46] stated that a good fit of Freundlich isotherm to an adsorption system implies there is adsorption on heterogeneous surfaces. It assumes heterogeneity in the surface binding sites; $\mathrm{FeO}-$ and $\mathrm{FeOH}$, present in the adsorbate as seen from FT-IR. $K_{f}$ values may be used to predict differences in the abilities of adsorbents to adsorb a particular adsorbate [26].

The exponent $1 / n$ is an index of the diversity of free energies associated with the adsorption of the solute by multiple components of a heterogeneous adsorbent [47]. For $1 / n<1$, adsorption is the predominant process implying strong interaction between adsorbent and adsorbate and vice versa. The $1 / n$ values for both adsorbents are negative implying strong interaction between the metal ion and $\mathrm{FeO}^{-} / \mathrm{FeOH}$ species. The strongest interaction however, as can be seen from Table 5, occurs with iron oxide adsorbent for both metal ions.

\subsection{Adsorption Kinetics}

The kinetics of $\mathrm{Co}(\mathrm{II})$ and $\mathrm{Ni}(\mathrm{II})$ ions adsorption were studied as a function of $\mathrm{pH}$ at a constant initial concentration of $700 \mathrm{ppm}$, adsorbate dose of $1 \mathrm{~g} / \mathrm{L}$ and contact time of 80 mins. The linear equation of the Lagergren's Pseudo-First Order, Pseudo-Second and Elovich Model Kinetic models are respectively given in Equations (4)-(6) below.

$$
\ln \left(Q_{e}-Q_{t}\right)=\ln Q_{e}-K_{1 t}
$$




$$
\begin{gathered}
\frac{t}{Q_{t}}=\frac{1}{h_{o}}+\frac{t}{Q_{e}} \\
Q_{t}=\frac{1}{\beta} \ln (\alpha \beta)+\frac{1}{\beta} \ln t
\end{gathered}
$$

where:

$Q_{e}$ and $Q_{t}$ are the adsorption capacity at equilibrium and at time t respectively $(\mathrm{mg} / \mathrm{g}), K_{1}$ is the rate constant of pseudo-first order adsorption $\left(\mathrm{min}^{-1}\right), K_{2}$ is the rate constant of pseudo second order adsorption $\left(\mathrm{mg}^{-1} \cdot \mathrm{min}^{-1}\right), h_{o}=K_{2} \cdot Q_{e}^{2}$ is the initial adsorption rate $\left(\mathrm{mg} \cdot \mathrm{g}^{-1} \cdot \mathrm{min}^{-1}\right), \alpha$ is the initial sorption rate $\left(\mathrm{mg} \cdot \mathrm{g}^{-1} \cdot \mathrm{min}\right)$, $\beta$ is the rate constant for desorption $\left(\mathrm{g} \cdot \mathrm{mg}^{-1}\right)$ during any one experiment.

The correlation coefficients were in the range of $0.0 .155-0.9652$ for pseudo-first-order kinetic model. Additionally, the $q_{e}$ values predicted by the pseudo-first-order model were not in agreement with the experimental values indicating that the model did not fit mechanism of cobalt and nickel adsorption.

The $R^{2}$ values for pseudo-second order model were in the range 0.9887 0.9993 and the predicted $q_{e}$ values agreed well with the experimental ones. The model is based on the assumption that the rate-limiting step may be a chemical adsorption involving valance forces through sharing or exchange of electrons between adsorbent and adsorbate [14]. This suggests that during the adsorption, there was chemisorption due to the sharing of electrons between the adsorbent surface and the d orbitals of cobalt and nickel ions. In Table 6 are listed the kinetic parameters for the three kinetic models and correlation coefficients for the adsorption of each metal ion.

From the table, the pseudo-second order kinetic model best fit (in the range 0.9887 to 0.9993 ) the kinetic data for both adsorbents and adsorbates. This indicates chemisorption and the formation of covalent bonds between the metal and adsorbents. Thus, the adsorption of cobalt and nickel ion onto iron oxide, goethite is a surface complexation process by inner sphere bonding. This analysis is in line with the universal uptake mechanism reported by Woodward et al. [48]; using synchrotron $\mathrm{x}$-ray absorption spectroscopy (EXAFS), they found that Co-O moieties form inner sphere bidentate complexes with $\mathrm{FeOH}$ groups of iron (oxy) hydroxides, and Co-Al moieties, with variable charged sites on alumina (kaolinite) form inner sphere bidentate complexes in mid-to-high $\mathrm{pH}$ range. Figure 8 compares the FTIR spectra of goethite and iron oxide before and after adsorption. From the graph, there is a general decrease in the intensity of the spectra after adsorption for both adsorbents indicating that the interaction of $\mathrm{Co}$ (II) and $\mathrm{Ni}$ (II) ions with the surface active sites increases their bond length. The FTIR results after adsorption thus confirms chemical interactions between $\mathrm{Co}$ (II) and $\mathrm{Ni}$ (II) ions and the surface active groups on the adsorbents. The correlation coefficients were in the range of $0.3752-0.8886$ for the Elovich kinetic model. This model is often applied to determine the kinetics of chemisorption of gases onto heterogeneous surfaces. This explains why the model is a poor fit for kinetic data of the adsorption of cobalt and nickel. 


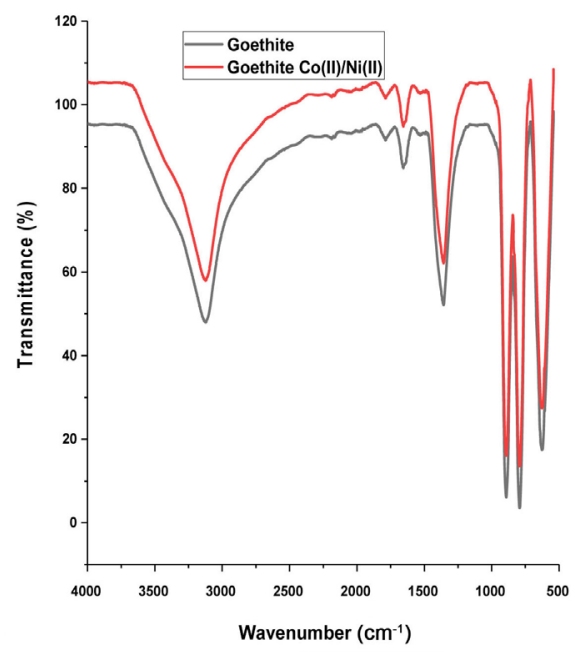

(a)

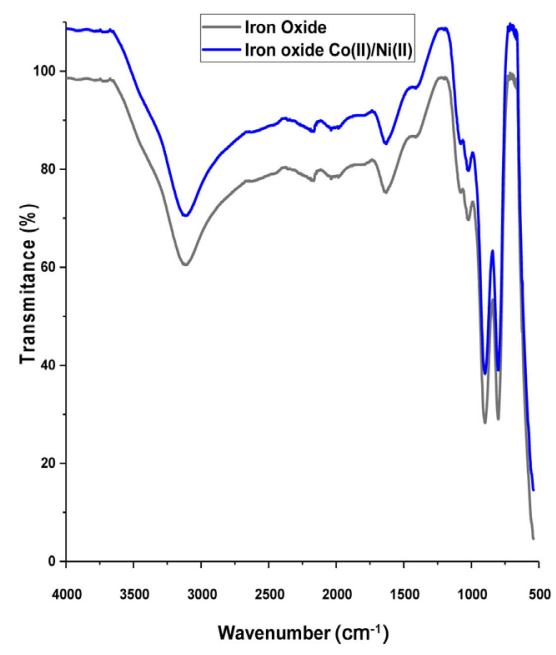

(b)

Figure 8. FTIR spectra of goethite (a) and iron oxide (b) before and after adsorption of $\mathrm{Ni}(\mathrm{II})$ ions.

Table 6. Rate constants and correlation coefficients of kinetic models.

\begin{tabular}{|c|c|c|c|c|}
\hline Models & Parameter & Iron Oxide & Goethite & Models \\
\hline \multirow{4}{*}{$\begin{array}{c}\text { Pseudo-first } \\
\text { order }\end{array}$} & \multirow{2}{*}{$R^{2}$} & $\mathrm{Co}(\mathrm{II})$ & 0.9652 & 0.7745 \\
\hline & & $\mathrm{Ni}(\mathrm{II})$ & 0.8529 & 0.155 \\
\hline & \multirow{2}{*}{$K_{1}$} & $\mathrm{Co}(\mathrm{II})$ & 0.0636 & 0.0008 \\
\hline & & $\mathrm{Ni}(\mathrm{II})$ & 0.0385 & 0.0003 \\
\hline \multirow{8}{*}{$\begin{array}{l}\text { Pseudo-second } \\
\text { order }\end{array}$} & \multirow{2}{*}{$R^{2}$} & $\mathrm{Co}(\mathrm{II})$ & 0.9887 & 0.9984 \\
\hline & & $\mathrm{Ni}(\mathrm{II})$ & 0.9936 & 0.9964 \\
\hline & \multirow{2}{*}{$\mathrm{h}_{\mathrm{o}}(\mathrm{mg} / \mathrm{g} \min )$} & $\mathrm{Co}(\mathrm{II})$ & 81.3 & 43.86 \\
\hline & & $\mathrm{Ni}(\mathrm{II})$ & 18.15 & 769 \\
\hline & \multirow{2}{*}{$K_{2}(\mathrm{~g} / \mathrm{mg} \min )$} & $\mathrm{Co}(\mathrm{II})$ & 0.010 & 0.004 \\
\hline & & $\mathrm{Ni}(\mathrm{II})$ & 0.003 & 0.114 \\
\hline & \multirow{2}{*}{$Q_{e}$} & $\mathrm{Co}(\mathrm{II})$ & 88.50 & 105.26 \\
\hline & & $\mathrm{Ni}(\mathrm{II})$ & 81.97 & 81.97 \\
\hline \multirow{6}{*}{ Elovich } & \multirow{2}{*}{$R^{2}$} & $\mathrm{Co}(\mathrm{II})$ & 0.8886 & 0.8392 \\
\hline & & $\mathrm{Ni}(\mathrm{II})$ & 0.8309 & 0.3752 \\
\hline & \multirow{2}{*}{$\beta(\mathrm{g} / \mathrm{mg})$} & $\mathrm{Co}(\mathrm{II})$ & 0.0693 & 0.1421 \\
\hline & & $\mathrm{Ni}(\mathrm{II})$ & 0.0888 & 0.2264 \\
\hline & \multirow{2}{*}{$\alpha(\mathrm{mg} / \mathrm{g} \min )$} & $\mathrm{Co}(\mathrm{II})$ & 123.91 & 157494 \\
\hline & & $\mathrm{Ni}(\mathrm{II})$ & 150.33 & $77 \times 10^{5}$ \\
\hline
\end{tabular}

\section{Conclusions}

The natural iron oxide sample was obtained and easily treated. Goethite was synthesized by chemical precipitation, and both adsorbents were characterized. PXRD identified the various phases present in each sample, SEM, the morphology and size of the particles, while FT-IR identified the various functional groups. 
From batch studies, equilibrium was attained after a contact time of $80 \mathrm{~min}$ for both adsorbents, an adsorbent dose of $0.1 \mathrm{~g}$ and $\mathrm{pH}=7$ were the optimal conditions obtained from varying these parameters, at metal ion concentration of $700 \mathrm{ppm}$. A percentage removal of $90.33 \%$ of $\mathrm{Co}$ (II) and $75.60 \%$ of $\mathrm{Ni}$ (II) ions by the natural iron oxide sample ( $50 \mathrm{ppm}$ adsorbate concentration, $0.1 \mathrm{~g}$ adsorbent at 80 mins) was also recorded. The best isotherm model fit for both adsorbents and both metal ions was the Freundlich model (monolayer adsorptions) with least square $\left(R^{2}\right)$ values in the range 0.976 to 0.9965 . Analysis of kinetic data presented the pseudo-second order kinetic model as the best-fit model (in the range 0.9887 to 0.9993 ) for both adsorbents and the two adsorbates. This indicates chemisorption and the formation of covalent bonds between the metal and adsorbents, and hence a good correlation between equilibrium and kinetics. From these observations, the natural iron oxide stands as an affordable material that can be applied as an effective adsorbent for treating effluents containing cobalt and nickel ions.

\section{Acknowledgements}

The authors are grateful to Dr. Chi Georges of De Montfort University, Leicester, UK for recording the FTIR and SEM-EDX spectra of adsorbents and to Prof. Dave Billing of University of the Witwatersrand, SA, for PXRD analysis. Special thanks to Prof. Claude Lecomte, for the travel bursary to SA, under the IUCr Crystallography in Africa initiative.

\section{Conflicts of Interest}

The authors declare no conflicts of interest regarding the publication of this paper.

\section{References}

[1] Duruibe, J.O., Ogwuegbu, M.O.C. and Egwurugwu, J.N. (2007) Heavy Metal Pollution and Human Biotoxic Effects. International Journal of Physical Sciences, 2, 112-118.

[2] Atibu, E.K., Devarajan, N., Laffite, A., Giuliani, G., Salumu, J.A., Muteb, R.C., Mulaji, C.K., Otamonga, J.P., Elongo, V., Mpian, P.T. and Poté, J. (2016) Assessment of Trace Metal and Rare Earth Elements Contamination in Rivers around Abandoned and Active Mine Areas. The Case of Lubumbashi River and Tshamilemba Canal, Katanga, Democratic Republic of the Congo. Geochemistry, 76, 353-362. https://doi.org/10.1016/j.chemer.2016.08.004

[3] Kitula, A.G.N. (2006) The Environmental and Socio-Economic Impacts of Mining on Local Livelihoods in Tanzania: A Case Study of Geita District. Journal of Cleaner Production, 14, 405-414.

[4] Mehler, W.T., Gagliardi, B., Keough, M.J. and Pettigrove, V. (2019) Evaluating Freshwater Mining Sediment Toxicity in Tasmania: Achieving Strong Multiple Lines of Evidence. Science of the Total Environment, 651, 1243-1252.

[5] Muruven, D.N. and Tekere, M. (2013) An Evaluation of the Cumulative Surface Water Pollution on Selected Areas within the Consolidated Main Reef Area, Roo- 
depoort, South Africa. Air, Soil and Water Research, 6, 121-130.

https://doi.org/10.4137/ASWR.S12997

[6] Kossoff, D., Hudson-Edwards, K.A., Howard, A.J. and Knight, D. (2016) Industrial Mining Heritage and the Legacy of Environmental Pollution in the Derbyshire Derwent Catchment: Quantifying Contamination at a Regional Scale and Developing Integrated Strategies for Management of the Wider Historic Environment. Journal of Archaeological Science: Reports, 6, 190-199. https://doi.org/10.1016/j.jasrep.2016.02.007

[7] Candeias, C., Ávila, P., Coelho, P. and Teixeira, J.P. (2018) Mining Activities: Health Impacts. In: Reference Module in Earth Systems and Environmental Sciences, Elsevier, ҐAmsterdam, Netherlands. https://doi.org/10.1016/B978-0-12-409548-9.11056-5

[8] Hossein, A., Sahebi-Shahemabadi, M., Rooholah, M. and Farrokh, A.S. (2009) Cobalt in Zahedan Drinking Water. Journal of Applied Sciences Research, 5, 2203-2207.

[9] World Health Organization (2011) Guidelines for Drinking Water Quality. 4th Edition, WHO, Geneva, Switzerland, 397.

[10] Wilson, L.J. (1994) Canada-Wide Survey of Acid Mine Drainage Characteristics. MEND Report 3.22.1, 9-20.

[11] Lupankwa, K., Love, D., Mapani, B.S. and Mseka, S. (2004) Impact of a Base Metal Slimes Dam on Water Systems, Madziwa Mine, Zimbabwe. Physics and Chemistry of the Earth, Parts A/B/C, 29, 1145-1151. https://doi.org/10.1016/j.pce.2004.09.017

[12] Meck, M., Love, D. and Mapani, B. (2006) Zimbabwean Mine Dumps and Their Impacts on River Water Quality-A Reconnaissance Study. Physics and Chemistry of the Earth, Parts $A / B / C, 31,797-803$. https://doi.org/10.1016/j.pce.2006.08.029

[13] Krishna, G.B. and Susmita, S.G. (2006) Adsorption of Chromium (VI) from Water by Clays. Industrial \& Engineering Chemistry Research, 45, 7232-7240. https://doi.org/10.1021/ie060586j

[14] Bulut, Y. and Tez, Z. (2007) Removal of Heavy Metals from Aqueous Solution by Sawdust Adsorption. Journal of Environmental Sciences, 19, 160-166. https://doi.org/10.1016/S1001-0742(07)60026-6

[15] Saad, S.A., Isa, K.M. and Bahari, R. (2010) Chemically Modified Sugarcane Bagasse as a Potentially Low-Cost Biosorbent for Dye Removal. Desalination, 264, 123-128. https://doi.org/10.1016/j.desal.2010.07.015

[16] Azraa, A., Jain, K., Tong, K.S., Rozaini, C.A. and Tan, L.S. (2012) Equilibrium, Kinetic and Thermodynamic Studies on the Adsorption of Direct Dye onto a Novel Green Adsorbent Developed from Uncaria Gambir Extract. Journal of Physical Science, 23, 1-13.

[17] Ömer, Y., Yalcin, A. and Fuat, G. (2003) Removal of Copper, Nickel, Cobalt and Manganese from Aqueous Solution by Kaolinite. Water Research, 37, 948-952. https://doi.org/10.1016/S0043-1354(02)00409-8

[18] Mekhemer, W.K., Hefneb, J.A., Alandisa, N.M., Aldayel, O.A. and Al-Raddadi, S. (2008) Thermodynamics and Kinetics of Co(II) Adsorption onto Natural and Treated Bentonite. Jordan Journal of Chemistry, 3, 409-423.

[19] Dragan, D., Dejan, S., Novica, D. and Miodrag, S. (2011) Thermodynamics of Reactive Dye Adsorption from Aqueous Solution on the Ashes from City Heating Station. Chemical Engineering Science, 8, 527-536.

[20] Wael, Q. and Mane, A.V. (2013) Characterization and Treatment of Selected Food Industrial Effluents by Coagulation and Adsorption Techniques. Water Resources and Industry, 4, 1-12. https://doi.org/10.1016/j.wri.2013.09.005 
[21] Evans, T.M. (2010) Use of Low Cost Adsorbents to Treat Industrial Wastewater. Unpublished Thesis, University of the Witwatersrand, Johannesburg, 28.

[22] Singh, R.S., Singh, V.K., Tiwari, P.N., Singh, U.N. and Sharma, Y.C. (2009) An Economic Removal of $\mathrm{Ni}(\mathrm{II})$ from Aqueous Solutions Using an Indigenous Adsorbent. The Open Environmental Engineering Journal, 2, 30-36. https://doi.org/10.2174/1874829500902010030

[23] Aredes, S., Klen, B. and Pawlik, M. (2013) The Removal of Arsenic from Water Using Iron Oxide Minerals. Journal of Cleaner Production, 60, 71-76. https://doi.org/10.1016/j.jclepro.2012.10.035

[24] Montes-Hernandez, G., Beck, P., Renard, F., Quirico, E., Lanson, B., Chiriac, R. and Findling, N. (2011) Fast Precipitation of Acicular Goethite from Ferric Hydroxide Gel under Moderate Temperature $\left(30\right.$ and $\left.70{ }^{\circ} \mathrm{C}\right)$. Crystal Growth \& Design, 11, 2264-2272. https://doi.org/10.1021/cg1016802

[25] Xiong, H.X. and Zhou, L.X. (2009) Preparation of Nanocrystalline Goethite $(\alpha-\mathrm{FeOOH})$ by Gel-Network Precipitation Method and Spectral Properties. PubMed, 29, 1590-1594.

[26] Mohapatra, M., Mohapatra, L., Singh, P., Anand, S. and Mishra, B.K. (2010) A Comparative Study on $\mathrm{Pb}(\mathrm{II}), \mathrm{Cd}(\mathrm{II}), \mathrm{Cu}(\mathrm{II}), \mathrm{Co}(\mathrm{II})$ Adsorption From Single and Binary Aqueous Solutions on Additive Assisted Nano-Structured Goethite. International Journal of Engineering, Science and Technology, 2, 89-103. https://doi.org/10.4314/ijest.v2i8.63784

[27] Ketcha, J.M., Tchatat, W.G.F. and Hambate, G.V. (2010) Adsorption of Ferricyanide Ion in Activated Carbon and $\gamma$-Alumina. E-Journal of Chemistry, 7, 721-726. https://doi.org/10.1155/2010/645479

[28] Marek, K., Durand-Vidal, S., Edward, M. and Jarl, B.R. (2004) Morphology of Synthetic Goethite Particles. Journal of Colloid and Interface Science, 271, 261-269. https://doi.org/10.1016/j.jcis.2003.10.032

[29] Mohapatra, M. and Anand, S. (2010) Synthesis and Applications of Nano-Structured Iron Oxides/Hydroxides-A Review. International Journal of Engineering, Science and Technology, 2, 127-146. https://doi.org/10.4314/ijest.v2i8.63846

[30] Cornell, R.M. and Schwertmann, U. (2003) The Iron Oxides: Structure, Properties, Reactions, Occurrences and Uses. Wiley-VCH Verlag GmbH \& Co., KGaA, Weinheim, 141-143, 253-296.

[31] Bhaskar, J.S., Parthasarathy, G. and Sarmah, N.C. (2008) Fourier Transform Infrared Spectroscopic Estimation of Crystallinity in $\mathrm{SiO}_{2}$ Based Rocks. Bulletin of Materials Science, 31, 775-779. https://doi.org/10.1007/s12034-008-0123-0

[32] Samira, B., Chandrappa, K.G. and Sharifah, B.A.H. (2013) Generation of Hematite Nanoparticles via Sol-Gel Method. Research Journal of Chemical Sciences, 3, 62-68.

[33] Chen, Y.-H. and Li, F.-A. (2010) Kinetic Study on Removal of Copper(II) Using Goethite and Hematite Nano-Photocatalysts. Journal of Colloid and Interface Science, 347, 277-281. https://doi.org/10.1016/j.jcis.2010.03.050

[34] Beyene, H.A. and Alemayehu, A.M. (2013) Removal of Ni(II) from Aqueous Solution Using Leaf, Bark and Seed of Moringa Stenopetala Adsorbents. Bulletin of the Chemical Society of Ethiopia, 27, 35-47. https://doi.org/10.4314/bcse.v27i1.4

[35] El Ouardi, M., Laabd, M., Oualid, H.A., Brahmi, Y., Abaamrane, A., Elouahli, A., Addi, A.A. and Laknifli, A. (2019) Efficient Removal of p-Nitrophenol from Water Using Montmorillonite Clay: Insights into the Adsorption Mechanism, Process Optimization, and Regeneration. Environmental Science and Pollution Research, 26, 
19615-19631. https://doi.org/10.1007/s11356-019-05219-6

[36] Abdus-Salam, N. and Adekola, F.A. (2005) The Influence of pH and Adsorbent Concentration on Adsorption of Lead and Zinc on a Natural Goethite. African Journal of Science and Technology, 6, 55-66. https://doi.org/10.4314/ajst.v6i2.55175

[37] Dwivedi, A.D., Dubey, S.P., Sillanpää, M., Kwon, Y.-N. and Lee, C. (2015) Distinct Adsorption Enhancement of Bi-Component Metals (Cobalt and Nickel) by Fireweed-Derived Carbon Compared to Activated Carbon: Incorporation of Surface Group Distributions for Increased Efficiency. Chemical Engineering Journal, 281, 713-723. https://doi.org/10.1016/j.cej.2015.07.004

[38] Awual, M.R., Alharthi, N.H., Hasan, M.M., Karim, M.R., Islam, A., Khaleque, M.A., Znad, H., Hossain, M.A., Halim, M.E. and Rahman, M.M. (2017) Inorganic-Organic Based Novel Nano-Conjugate Material for Effective Cobalt(II) Ions Capturing from Wastewater. Chemical Engineering Journal, 324, 130-139. https://doi.org/10.1016/j.cej.2017.05.026

[39] Guo, N., Su, S.-J., Liao, B., Ding, S.-L. and Sun, W.-Y. (2017) Preparation and Properties of a Novel Macro Porous $\mathrm{Ni}^{2+}$-Imprinted Chitosan Foam Adsorbents for Adsorption of Nickel Ions from Aqueous Solution. Carbohydrate Polymers, 165, 376-383. https://doi.org/10.1016/j.carbpol.2017.02.056

[40] Yang, S.T., Li, J.X., Shao, D.D., Hu, J. and Wang, X.K. (2009) Adsorption of Ni(II) on Oxidized Multi-Walled Carbon Nanotubes: Effect of Contact Time, pH, Foreign Ions and PAA. Journal of Hazardous Materials, 166, 109-116. https://doi.org/10.1016/j.jhazmat.2008.11.003

[41] Mobasherpour, I., Salahi, E. and Ebrahimi, M. (2012) Removal of Divalent Nickel Cations from Aqueous Solution by Multi-Walled Carbon Nano Tubes: Equilibrium and Kinetic Processes. Research on Chemical Intermediates, 38, 2205-2222. https://doi.org/10.1007/s11164-012-0537-6

[42] Wang, Q., Li, J., Chen, C., Ren, X., Hu, J. and Wang, X. (2011) Removal of Cobalt from Aqueous Solution by Magnetic Multiwalled Carbon Nanotube/Iron Oxide Composites. Chemical Engineering Journal, 174, 126-133. https://doi.org/10.1016/j.cej.2011.08.059

[43] Swayampakula, K., Boddu, V.M., Nadavala, S.K. and Abbur, K. (2009) Competitive Adsorption of Cu (II), Co (II) and Ni (II) from Their Binary and Tertiary Aqueous Solutions Using Chitosan-Coated Perlite Beads as Biosorbent. Journal of Hazardous Materials, 170, 680-689. https://doi.org/10.1016/j.jhazmat.2009.05.106

[44] Roy, A. and Bhattacharya, J. ((2013)) A Binary and Ternary Adsorption Study of Wastewater $\mathrm{Cd}(\mathrm{II}), \mathrm{Ni}(\mathrm{II})$ and $\mathrm{Co}(\mathrm{II})$ by $\gamma$ - $\mathrm{Fe}_{2} \mathrm{O}_{3}$ Nanotubes. Separation and Purification Technology, 115, 172-179. https://doi.org/10.1016/j.seppur.2013.05.010

[45] Tofighy, M.A. and Mohammadi, T. (2011) Adsorption of Divalent Heavy Metal Ions from Water Using Carbon Nanotube Sheets. Journal of Hazardous Materials, 185, 140-147. https://doi.org/10.1016/j.jhazmat.2010.09.008

[46] Krishnie, M., Ruella, S., Evans, T.M., Maurice, S.O. and Aoyi, O. (2011) Removal of Nickel from Wastewater Using an Agricultural Adsorbent. Water SA, 37, 41-46. https://doi.org/10.4314/wsa.v37i1.64105

[47] Wang, C., Boithias, L., Ning, Z., Han, Y., Sauvage, S., Sánchez-Pérez, J.-M., Kuramochi, K. and Hatano, R. (2017) Comparison of Langmuir and Freundlich Adsorption Equations within the SWAT-K Model for Assessing Potassium Environmental Losses at Basin Scale. Agricultural Water Management, 180, 205-211. https://doi.org/10.1016/j.agwat.2016.08.001

[48] Woodward, G.L., Peacock, C.L., Thompson, O.R., Otero-Fariña, A., Brown, A.P. 
and Burk, I.T. (2018) A Universal Uptake Mechanism for Cobalt(II) on Soil Constituents: Ferrihydrite, Kaolinite, Humic Acid, and Organo-Mineral Composites. Geochimica et Cosmochimica Acta, 238, 270-291.

https://doi.org/10.1016/j.gca.2018.06.035 